\title{
ANALYSIS OF VIBRATION WHEN APPLICATION OF PROGRESSIVE GRINDING WHEELS
}

This investigation was undertaken to compare the performance of grinding wheels containing newly developed "seeded gel" aluminum oxide abrasive with the wheels containing conventional monocrystalline aluminum oxide. The experiments were carried out on the surface grinder BPH 20 over a wide range of removal rates with two grinding wheels on hardened bearing-steel specimens. It was found that the wheels containing "seeded gel" abrasive required less grinding power and gave higher grinding stability than monocrystalline abrasive wheels of the same grade with better surface waviness. The potential improvement in productivity using the "seeded gel" abrasive wheels was estimated. Optimal removal rates with the $S G$ wheel are higher than the one for conventional monocrystalline aluminum oxide.

\section{Introduction}

Grinding is a widely used machining process in applications requiring high production rates and very good dimensional accuracy and surface finish. It is also one of the more complex metalworking processes and one of the less understood. Consequently, successful use of grinding in practice is highly dependent on the level of expertise of the machinist and engineer. Grinding is also viewed as an unpredictable process because of the large number of variables involved and inadequate understanding of the relationships between those variables and the grinding process performance. That is particularly true of vibration in grinding operations, commonly referred to as grinding chatter [1].

Grinding chatter poses many of the same problems that chatter in other machining operations presents. Chatter results in undulations or roughness on the grinding wheel or workpiece surfaces and is highly undesirable. One form of grinding chatter, referred to as self-excited chatter, is usually eliminated or reduced by lowering metal removal rates. Also, grinding wheel surface unevenness resulting from chatter necessitates frequent wheel redressing. Thus, chatter results in a worsening of surface quality and lowers machining productivity. Those limitations are particularly severe, since grinding operations are used in applications involving high production quantities and stringent dimensional accuracy and surface finish requirements $[1,2]$. Improved productivity and workpiece surface finish would, therefore, result from better understanding of grinding chatter $[1,3]$.

Except application conventional monocrystalline aluminum oxide recent developments have lead to the use of chemical ceramic "sol gel" technology to produce a new class of alumina abrasives [4]. This process involves converting a colloidal dispersion or hydrosol containing goethite in a mixture with solutions or other sol precursors to a semi-solid gel to restrain the mobility of the components, drying to a glassy state, crushing to the required grain size, and firing at about $1300{ }^{\circ} \mathrm{C}$. Subsequent developments resulted in a modification to the process whereby the gel is "seeded" with submicron alpha alumina particles before drying [3, 4]. The produced "seeded gel" (SG) abrasive grit consists of sub-micron size crystalline particles which can separate from the abrasive grit by wear during grinding. It was reasoned that this type of microcrystalline fracture wear would keep the abrasive sharper than conventional abrasives which become dull by the formation of wear flats on their tips, thereby reducing bulk wheel wear rates, improving grinding ratios, enhancing the ability of the wheel to hold form and finish, and providing higher removal rates with lower power $[3,4]$. This investigation was undertaken to compare the performance of grinding wheels containing newly developed "seeded gel" aluminum oxide abrasive with wheels containing conventional monocrystalline aluminum oxide. This investigation is based on analyze of vibration and its influence on quality of ground surface.

\section{Conditions of experiment}

Grinding tests were performed under surface grinding conditions using the grinding machine BPH 20. The work pieces, used in the experiments were made of $100 \mathrm{Cr} 6$ bearing steel hardened to $62 \mathrm{HRC}(100 \times 10 \times 60 \mathrm{~mm})$. The grinding performances of two types of wheels of the same hardness grade were compared: a monocrystalline alumina wheel (A99 $01250 \times 20 \times 7638$ A 60 JVS) such as commonly used for grinding of bearing steels, a "seeded gel" wheel $(5 \mathrm{SG} 01250 \times 20 \times 7660 \mathrm{JVX}$ - containing $50 \%$ of SG grain in the wheel).

Cutting conditions:

cutting depth $\quad-a_{p}=0.01 \mathrm{~mm}$ to $0.04 \mathrm{~mm}$,

\footnotetext{
* Jana Steiningerova, Miroslav Neslusan, Stefan Nemeth

Department of Machining and Automation, Faculty of Mechanical Engineering, University of Zilina, Slovakia, E-mail: jana.steiningerova@fstroj.utc.sk
} 
feed

cutting speed

cutting fluid

$$
\begin{aligned}
& -v_{f}=8\left(\mathrm{~m} \cdot \mathrm{min}^{-1}\right) \\
& -v_{c}=28.39 \mathrm{~m} \cdot \mathrm{s}^{-1} \\
& \text { - EMULZIN H (2\% concentration). }
\end{aligned}
$$

Analysis of vibration was carried out through measurement of grinding forces (Fig. 1). Grinding forces were measured by piezoelectric dynamometer KISTLER type 9257A. A personal computer collects information from the dynamometer in the predetermined points of the grinding cycle. Analysis of the collected information were carried out in the software DasyLab 3.5. Surface topography was analyzed through its waviness (applied device MP125).

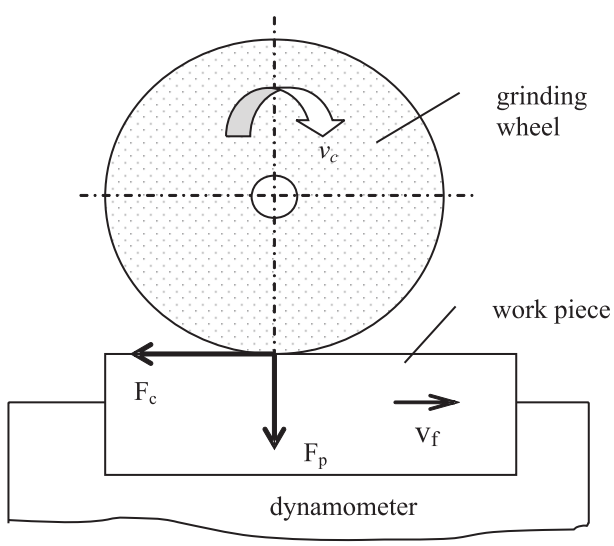

Fig. 1 Grinding forces $F_{c}$ and $F_{p}$

\section{Results of experiment}

Grinding forces were analyzed in two frequency zones. The static components represent grinding force up to frequency $10 \mathrm{~Hz}$, the dynamic forces above the frequency $10 \mathrm{~Hz}$. Records of grinding forces are illustrated in Figs.2 and 3. These records represent the stage of a worn grinding wheel. There is a visible difference in the amplitude of vibration between the conventional and SG wheel. The negative values in Fig. 2 are caused by persistence of grinding system.

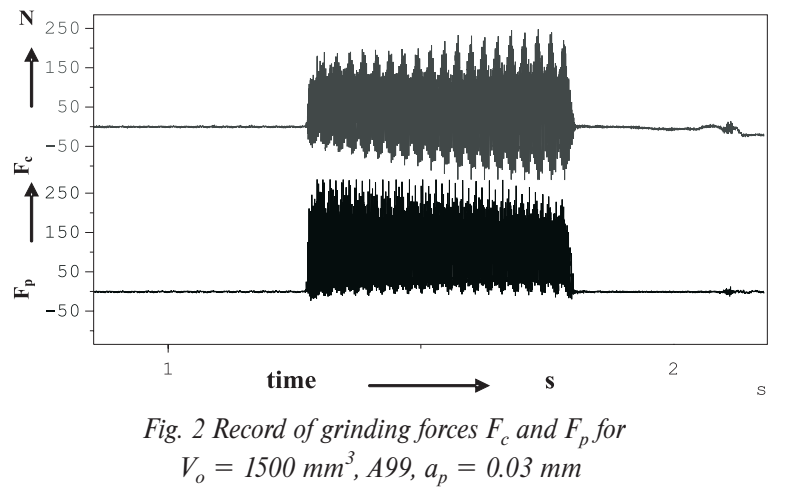

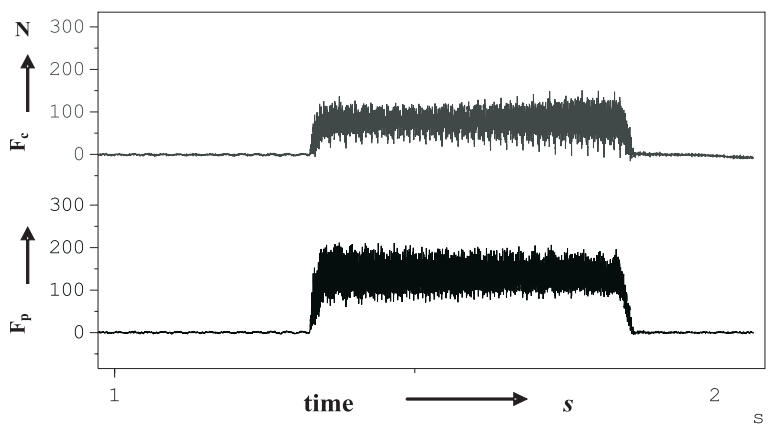

Fig. 3 Record of grinding forces $F_{c}$ and $F_{p}$ for

$V_{o}=1500 \mathrm{~mm}^{3}, 5 S G, a_{p}=0.03 \mathrm{~mm}$

The dynamic components of grinding forces were analyzed though the RMS values (the RMS value is the most relevant measure of amplitude because it both takes the time history of the wave into account and gives an amplitude value which is directly related to the energy content, and therefore the destructive abilities of the vibration). From the results in Fig. 4 it can be seen that the RMS values progressively increase the same way with the continued grinding for both wheels. Next, there is visible only a slow rise of the RMS values after the dressing (approximately up to $V_{o}=$ $=500 \mathrm{~mm}^{3}$ ). This interval represents the stable area of the grinding process. On the other hand, there is following intensive increase of RMS values. This stage represents the worn grinding grains. The grinding wheel should be redressed. Fig. 4 illustrates that there is no significant difference in the RMS values between the conventional and SG grinding wheels under the low cutting depth. On the other hand, there is a significant difference under the higher cutting depth. When compared with the conventional wheel (Fig. 5) there is no visible intensive increase of the RMS values for the 5SG wheel. This difference is related to self-sharpening effect of SG grain under the higher cutting forces generated by higher cutting depths (higher material removal rates). When working with lower cutting forces (lower cutting depths), it is necessary to produce the microchipage of the grains by implementing a dressing process.

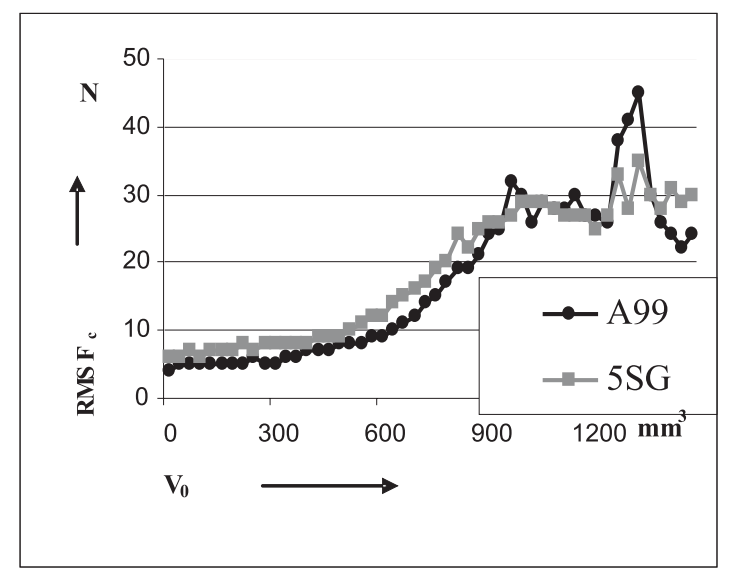

Fig.4 Influence of grinding grain wear on the RMS value of cutting force, $a_{p}=0.01 \mathrm{~mm}$ 
Analysis of self-excited vibration is illustrated by frequency specters in Figs. 6 and 7. There is formation of waviness on the grinding wheel surface. This waviness can be identified through the frequency of approximately $400 \mathrm{~Hz}$. This frequency is given by a number of revolutions of the grinding wheel per one second (40 times) and the number of waves on the grinding wheel surface (in this case 10 waves). Figs. 6 and 7 illustrate that this dominant frequency is higher for a conventional wheel than for a $5 \mathrm{SG}$ wheel. Then, the number of waves on the 5SG grinding wheel surface is higher because the dominant frequency is higher. This aspect is suitable considering the formation of waviness on the ground surface (the higher number of waves is obviously related to the lower amplitudes of waves). The lower amplitude and the higher frequency for the $5 \mathrm{SG}$ wheel lead to the lower surface waviness. This comparison is illustrated in Figs. 8 and 9. Amplitudes of waves of the ground surface after grinding with the conventional wheel are significantly higher than the ones generated by the 5SG wheel.

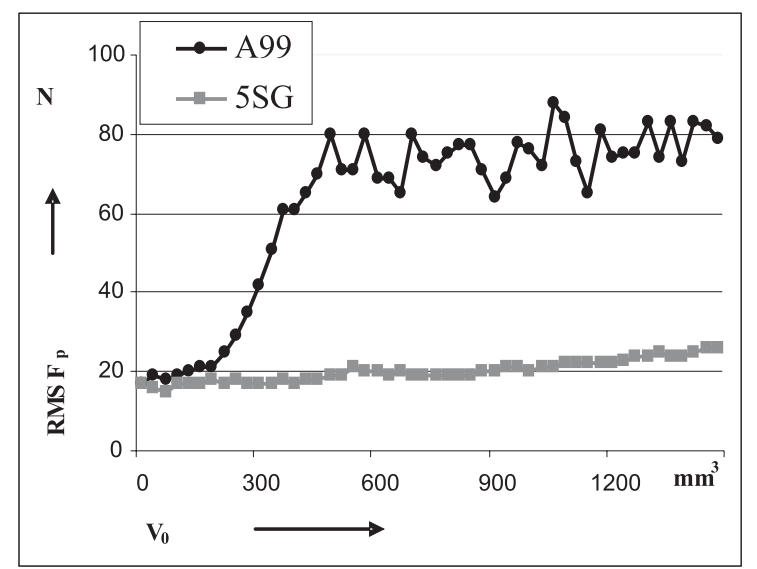

Fig.5 Influence of grinding grain wear on the RMS value of cutting force, $a_{p}=0.03 \mathrm{~mm}$

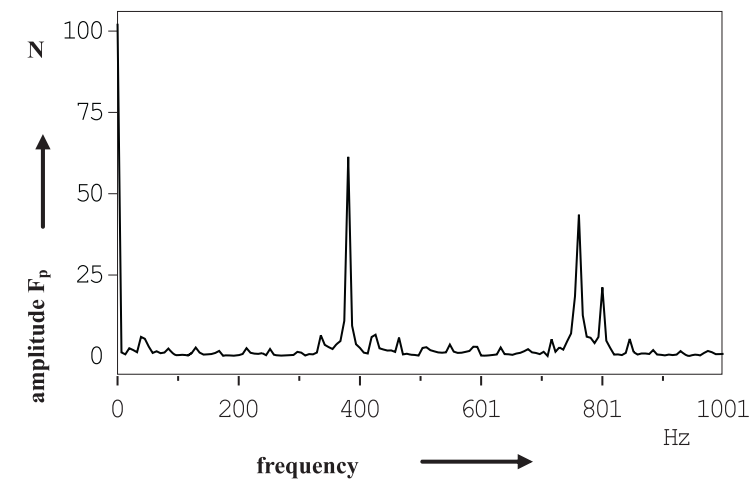

Fig.6 Frequency - amplitude spectrum for $V_{o}=1500 \mathrm{~mm}^{3}$, $a_{p}=0.03 \mathrm{~mm}$ A99 grinding wheel

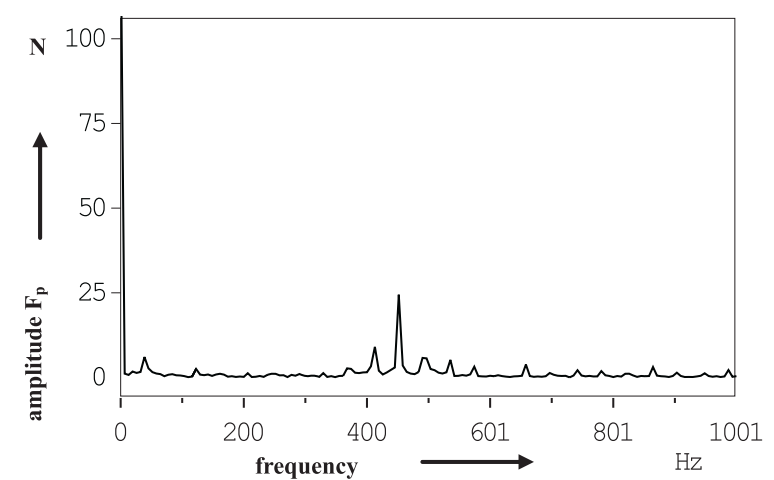

Fig. 7 Frequency - amplitude spectrum for $V_{o}=1500 \mathrm{~mm}^{3}$, $a_{p}=0.03 \mathrm{~mm} 5 S G$ grinding wheel

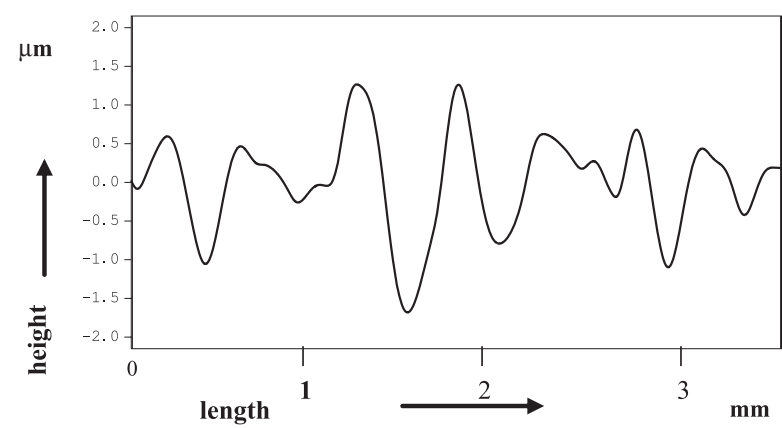

Fig. 8 Waviness of ground surface generated by conventional $\mathrm{Al}_{2} \mathrm{O}_{3}$ wheel, $a_{p}=0.03 \mathrm{~mm}, V_{o}=1170 \mathrm{~mm}^{3}$

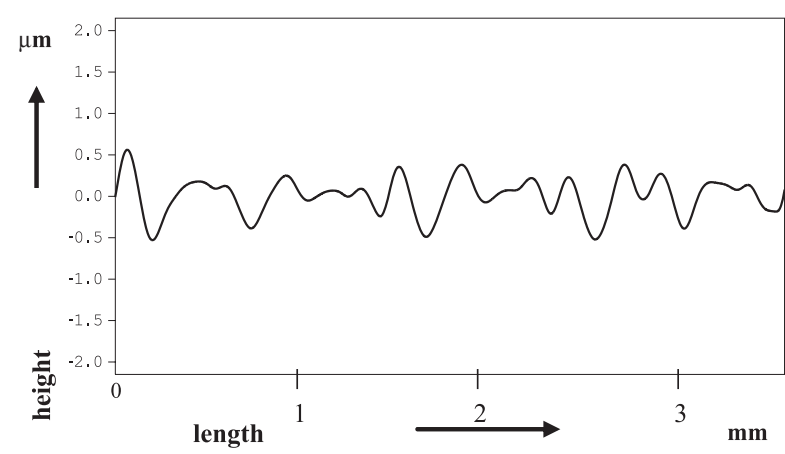

Fig. 9 Waviness of ground surface generated by 5SG wheel,

$$
a_{p}=0.03 \mathrm{~mm}, V_{o}=1170 \mathrm{~mm}^{3}
$$

\section{Conclusion}

The objective of this investigation was to compare the performance of grinding wheels containing newly developed "seeded 
gel" abrasive with the wheels containing conventional monocrystalline alumina. It was found that $5 \mathrm{SG}$ abrasives lowered the intensity of vibration and surface waviness compared with the monocrystalline abrasive wheels of the same grade. The optimal removal rates for the "seeded gel" abrasive wheels were higher than for monocrystalline wheels. Similar results can be achieved by application of modified technology known as Targa gel wheel (TG wheels). Moreover, there are other aspects of SG and TG wheels application. First of all, it is higher $\mathrm{G}$ ratios for SG and TG wheels in comparison with the conventional wheel, the lower temperatures in the contact of grinding wheel and workpiece, more suitable state of residual stresses and longer interval between dressings.

\section{Acknowledgement}

The authors would like to acknowledge the financial support given by the VEGA for this project (project No 1/2080/05) included in the research programme of the University of Zilina.

\section{References:}

[1] TONSHOFF, H. K., FRIEMUTH, T., BECKER, J. C: Process Monitoring in Grinding, Annals of the CIRP, 51/2/2002, p. 551

[2] NESLU_AN, M., TUREK, S., MINICH, R.: Study of vibration in grinding through the analysis of grinding force (in Slovak), Strojárska technológia 2004, Súlov, pp. 177-184

[3] TUREK, S. - MINICH, R. - NESLUŠAN, M.: Experimental Investigation of Chatter at SG Grinding Wheels Application, $11^{\text {th }}$ International scientific conference, Žilina, 2003

[4] UHLMAN, E., STARK, C.: Potentiale von Schleifwerkzeugen mit mikrokristalliner Schleifen, Honen und Polieren, Vulkan Verlag, Essen, 1997. 